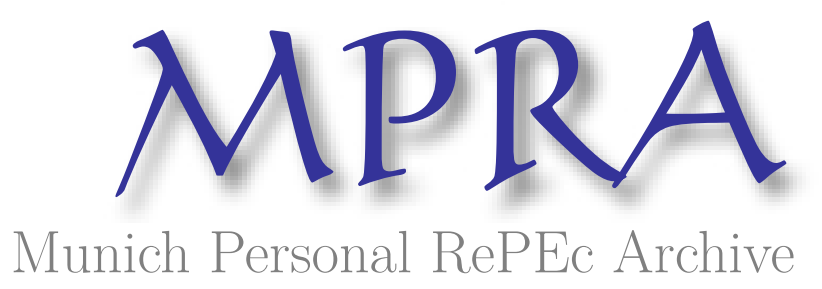

\title{
Institutions and initial conditions in transition: reconciling neo-institutional and neo-classical conceptions
}

Vonnegut, Andrew

Alliance Equity Group LLC

2009

Online at https://mpra.ub.uni-muenchen.de/24563/

MPRA Paper No. 24563, posted 22 Aug 2010 23:50 UTC 
Institutions and Initial Conditions in Transition: Reconciling Neo-institutional and Neo-classical Conceptions

\title{
Author Name and Affiliation
}

Andrew Vonnegut

Alliance Equity Group LLC

\begin{abstract}
Much empirical research has highlighted the importance of institutions and initial conditions in the transition to a market economy. However, relatively little is still know about how these factors directly affect growth paths. This paper explores how institutional factors and initial conditions explicitly impact consumer and firm decisions. Simulations are run on a simple growth model modified to reflect institutional conditions during transition. The model generates a series of growth paths that lend insight into how different institutional structures affect growth dynamics. Policies that work under certain institutional circumstances, such as the "big bang," may not work under others.
\end{abstract}

\section{Keywords}

Economic Transition, Economic Growth, Institutions, Simulation

Summer, 2010 


\section{INTRODUCTION}

Over the past 17 years, centrally planned economies have transitioned to more market-based systems. The basic growth goals of transition were shared across economies with very different economic environments and starting from very different initial conditions. Although similar policies were prescribed and followed, the outcomes to date have differed considerably across these economies. These disparities present an unprecedented opportunity to study and dissect the factors that underpin successful and failed attempts at economic change and development.

The recent transitions from centrally planned to market economies has yielded a rich set of economic data. Taking advantage of this wealth of data, the last decade has spawned an extensive literature of empirical, econometric analyses of the effects of policies, initial conditions and institutions on performance during transition. These papers focused on determining which, if any, of these sets of factors influences, or does not influence, outcomes in transition. The literature has been responsible for revealing a much deeper understanding of, to what degree, these factors are related to particular outcomes.

These analyses answer "what" to the extent that the data and available statistical methods allow. It is now broadly understood that institutions and initial conditions do affect growth paths. However the questions of "how" or "why" are not answered as sufficiently. In other words, it is not clearly understood how institutions and initial conditions impact growth, or why certain outcomes should be expected to emerge from a particular combination of initial conditions, institutions and policies. The usual causality issues in econometrics, in addition to multicollinearity and imperfect measurement of subjective concepts all keep a coherent theory from emerging that would help answer these latter questions. This has been noted as lacking in the literature, especially in explaining the output collapse and showing how institutions affect growth [Beck and Laeven 2006, Campos and Coricelli, 2002]. Though additional information will undoubtedly be coaxed from the data in the coming years, the answers to these questions using the techniques at hand have so far been dissatisfying. 
This paper takes a step back from the literature based on econometric tests to look more at how and why some of the factors identified in the empirical literature can influence outcomes. A subset of initial conditions and institutions are examined which are consistently noted as significant in the empirical literature. These conditions are examined in a growth theoretical context to see specifically what effects they may have dynamics and outcomes during transition, or how different institutional environments can lead to different results using the same basic neoclassical growth model. Of particular interest is how and why institutions and initial conditions can effect economic outcomes through their effects on production function characteristics, agents' decision making, and financial intermediation.

To explore these ideas, simulations are run on a basic Ramsey type growth model. In the place of some standard assumptions, the model contains parametric and functional proxies for some of the institutional characteristics identified as important in the empirical literature. These parameters and functions are then roughly calibrated to replicate initial conditions and the institutional environment in three categories of transitional economies: successful transition (e.g. Hungary, Poland, Czech Republic, Baltic Countries); poor performance in transition, but with reform attempts (e.g. Moldova, Kirgizstan, Ukraine), and; poor performance with no reform (e.g. Uzbekistan, Turkmenistan). The results indicate that initial conditions, policies, and institutions are all important and can affect outcomes in transition. These factors also affect the transition path in the model in a way that is consistent with the actual observed growth paths of those categories of economies. Empirically it is apparent that the convergence predicted by neoclassical growth theory did not happen among all the transitional economies. The analysis and model help show why, as well as the impact of including or ignoring at least certain institutional factors in the development of policy. In one result, the model shows that imposing reforms early on (as with "big bang" programs) can be a good default policy paradigm. However, when institutional conditions are very poor, reforms may still lead to long periods of capital depletion. This result has also been borne out in reality.

Formalizing institutional factors into theory will help in understanding the growth or lack thereof in all countries for which a full set of market institutions do not exist. This paper reviews some 
of the main issues and challenges. The challenges are many, with some of the discussion in this paper admittedly unsatisfying. However, since the impact of institutions on growth has become more widely accepted, it is advantageous to begin moving in that direction. The next section presents an overview of the literature to date, mainly outlining what economists have come to believe are the main factors affecting transition. Section III delves more deeply into the way institutions may impact transition, and gives the main arguments for the model design. In Section IV, the model is specified. Since derivation of the basic model is standard by this time, only the deviations from the standard Ramsey type model are discussed. Section V presents the simulations modeled under different institutional and initial conditions, showing how these affect convergence to the steady state. Section VI offers conclusions and possible extensions.

\section{FACTORS AFFECTING TRANSITION}

Early analysis of economic transition focused on policy, and especially the lengthy, and still not fully resolved, debate on gradual versus rapid transition. The literature is voluminous, and will not be listed here. See Svejnar, [2002] for a survey and extensive bibliography on the main work on transition to that date. Also fairly early on, a number of authors identified the importance of institutions in transition, largely in theoretical works [Bromley, 1993, Greif and Kandel, 1993, Schmieding, 1993, Yavlinsky and Braguinsky, 1994]. These considerations were also integrated on a limited basis into many micro analyses of certain aspects of transition, especially privatization [Frydman and Rapaczynski, 1994, Schenk, 1992, Murrell and Wang, 1993, Wang, 1993,]. The themes, sometimes combined with discussions on initial conditions, continued into the later literature as well [Kolodko, 1999, Linn, 2002, Marangos, 2002].

Arguably the earliest seminal, theoretical research explicitly accounting for how institutional arrangements can affect aggregate output growth was by Blanchard and Kremer [1997]. The paper addresses the inapplicability of the set of institutions built up under central planning to decentralized decision making, and the institutional gap that develops when market conditions begin to apply, but when market institutions are lacking. The resultant state, which the authors appropriately deem "disorganization," is characterized by lower output overall until new institutional arrangements 
emerge. Most other early theoretical literature focused on sequencing and political economy factors [i.e. Aghion and Blanchard, 1994, Dewatripont and Roland, 1995].

When enough data became available to carry out the first empirical studies, authors tended to focus on the relative influence of policies and initial conditions on outcomes [Berg et. al. 1999, de Melo et al. 1996, de Melo et al, 1997, Fischer et. al. 1996, Fischer and Sahay, 1999 and 2000, Kolodko, Krueger and Ciolko, 1998, Selowski and Martin, 1997, Falcetti et al., 2002]. Most of these studies found a positive relationship between both policies and initial conditions and growth in transition, though not a consensus on the relative merits of each.

Later empirical work reinforced the importance of initial conditions, but emphasized that they could often be overcome with good policy [Havrylyshyn and Van Rooden, 2003], or that both mattered [Heybey and Murell, 1998]. Others argued that given the importance of other factors, the data showed that shock therapy, or even policies overall, cannot be relied upon alone to bring gains [Radulescu and Barlow, 2002], though also concluded that the role of market institutions needs to be looked at more closely. The conclusion that initial conditions had no effect was challenged in a later edition of the same journal [Rzonca and Cizkowski, 2003]. Furthermore, a more recent study by Rodrik [2005] highlights some of the data issues, such as endogeneity, inherent in growth regressions - calling into question much of the previous work done.

In due time, as better proxies for institutional quality and change became available, the empirical literature shifted in that direction. ${ }^{1}$ It was partially spurred on by a growing acceptance in the mainstream literature of the neo-institutional economics pioneered by North [1991], Williamson [1985] and others. Much of the later empirical work took institutional factors into account, finding them to be statistically significant, sometimes along with initial conditions [Havrylyshyn, 2001, Campos and Coricelli, 2002], or sometimes not [Bardhan, 2005, Chousa et al., 2005, Grogan and Moers, 2001, Radek and Susjan, 2005]. Both Beck and Laeven [2006] and Godoy and Stiglitz [2006] found institutions to be the most relevant of factors affecting performance in transition, with policies including shock therapy being almost irrelevant as a factor in longer term performance. On a more micro-level, Bhaumik and Estrin [2007] identified institutions as a critical factor in Russian firm-level 
growth. Beck and Laeven also empirically identified a positive correlation between initial conditions and institutional development, though Falcetti et. al. [2006] found these to decrease over time.

Relatedly, Aixala and Fabro [2008] showed in an overall growth context the importance of income in determining which institutions matter most. Rodrik et. al. [2004] found institutions to be the most important factor contributing to growth among those tested. (See these sources also for a more complete review of the empirical literature.) Murrell [2006] provides an excellent overview of how perceptions on the role of institutions evolved over time in the literature.

Though the institutional impacts tested for were statistically significant, it is still worth noting, as many authors do, that the data used in the models were often poor proxies for the formal and especially informal institutional conditions prevalent in the economies at the time. There are certain aspects of institutions that are simply difficult to quantify. Also, most available data measure the nominal presence of formal institutions more effectively than they measure the quality of the institutions. The latter is critical to economic outcomes and is not a foregone conclusion.

The data problems pointed out by Rodrik [2005] also exist when regressing multivariable equations involving both initial conditions and institutions. The imperfect nature of the indicators means that many of the variables chosen can be proxies for both factors. For example, "time under communism" is a common initial condition regressor, but can also be highly correlated with the presence of market economy supporting institutions, both formal and informal. Specification problems have been serious, mainly in the quality of proxies, in their potential endogeneity and in the collinearity issues mentioned directly above.

There will likely be additional rounds of research using new techniques and new proxies for the often essentially qualitative variables involved. Some of this additional research may discount the studies cited directly above. Regardless of what methodological issues are to be worked out, it does appear that institutions have earned their right to stay in the mainstream transition literature. If anything, there is evidence that a more rigorous dealing with the data imperfections will lead to a greater imputed role for institutions. Beyond establishing causality, we need to learn to understand and specifically account for institutional dynamics. 


\section{INSTITUTIONAL IMPACTS ON GROWTH IN TRANSITION}

Viewed through the lens of neoclassical growth theory, the problem of transition is partially one of removing rigidities so that countries can move toward their steady state output levels. That said, given the breadth of changes and the range of policies enacted during transition, it is unclear what constitutes removing a barrier to reaching a hypothetical inherent steady state level of output, versus changes that affect the steady state level. This debate is tangled deeply in questions of the relative permanence of structural factors in economies. Significantly, conditional convergence rather than absolute convergence is most validated by the empirical work. Groups of countries sharing certain characteristics have turned out differently than others sharing other characteristics. In the nontransitional growth literature, broad, cross sectional research has shown that factors such as education, life expectancy, fertility, and government consumption help determine what steady state level the economy will reach. Countries that share characteristics across these categories increase their probability of converging to similar steady state income levels. See Barro and Sala-i-Martin [2005] for a discussion and extensive bibliography. The research cited in the previous section indicates that for the transitional economies, institutional and initial conditions may differentiate countries into “convergence peer groups."

A depressing empirical curiosity that does not fit well with growth theory is how capital depletion and negative growth are dealt with. In the most pathological country cases, such as the Ukraine and Moldova, incomes have dropped well-below their pre-transition levels and have stubbornly refused to improve. It is insufficient to say that the steady state was higher under communism than under the failed market economy that subsequently developed. Understanding more specifically how the institutional factors and initial conditions identified in the empirical literature play on growth may help shed some light on this question. As noted previously, an early piece of work in this area was Blanchard and Kremer, who state "Transition may lead to a large decline in output until new institutions can be created" [1997, pg. 1122]. Standard growth theory, not taking institutions into account, has not been able to address this issue. 
Before moving further, institutions need to be defined, to the extent that is possible. Using the definitions from North [1990, 2005] is probably safest and most accepted in the literature. North [2005] defines institutions as “...the constraints that humans place on human interaction...[and]...define the opportunity set in the economy." See Dixit [2005] and Acemoglu and Robinson [2008] for a more detailed taxonomy and discussion of variable impacts on growth. The next level of definition, into formal and informal groupings, is more challenging. During transition there are a large number of both formal and informal institutions that differ from the ideal set of market institutions. Formal institutions are those that are encoded and imposed within a system. Those integral to the transitional context include the system of codified law, including property rights, codified individual rights, contract law and the attendant enforcement mechanisms.

In addition to formal institutions, key informal institutions, including social norms, culture, and traditions, help to define behavioral norms. Even societies without codified law can have well established and often rigid codes governing economic behavior. Informal and formal institutions often play the complementary or even reinforcing roles in an economy, since they both may deal with rules of the same interaction between agents. As Dixit [2005] and others have noted, many of the transactional roles of formal institutions are in their absence played out in the informal sphere, often very effectively. However, they could otherwise conflict with each other. As such, formal institutions generally are implemented more effectively when they are consistent with, or even seek only to codify, underlying informal norms. Both types of institutions affect how agents respond to incentives, alone and in groups. Though, the difficulty of measuring the strength of informal institutions, rather than merely the presence of formal ones, is a topic that the empirical work is yet to overcome. The considerable reliance on proxies for the presence of formal institutions is understandable given the indicators available. That formal institutional structures have been built without changing the way the economy actually works, however, has been the bane of institution building exercises across all transitional economies. This, however, is a topic for another group of research.

As discussed, there is a significant gap between the empirical analyses showing the importance of institutions, and an understanding of how institutions actually affect growth paths. The 
absolute convergence as predicted by the basic neoclassical growth model did not occur during transition. However, it is less clear specifically how varying institutions and initial conditions may have precluded full convergence, or may have contributed to the different levels of convergence observed in different economies. In this paper a basic growth model is constructed to begin to look at this question. In the model, four deviations from the standard assumptions of growth models are highlighted. Three deal with institutions and one with initial conditions. These are noted below and the relayed into functional forms and linkages in the model to follow.

1. Initial condition: Large amounts of under-productive capital locked into a rigid, non-market system. The capital stock in the formerly centrally planned economies was extremely large, even relative to the wealthier industrial market economies. Much of it, however, was not highly productive or was locked for various reasons into low productivity uses. The high fixed capital stock and fixed costs in enterprises initially dilute the effect of and returns to new capital entering the system. Even small business start-ups had to content with competition from assets obtained under non-market terms, lowering their returns. The "Inada" condition of infinite returns to capital fully depends implicitly on this non-dilution. In the transitional context (if in any context) it would not hold even as "effective" capital stocks dropped to low levels.

2. Informal and formal institution: Incomplete information in markets, mainly related to inputs, outputs, and capital pricing and terms. This contributes to misallocation, non-competitive pricing, and managerial errors, leading to a low level of capital productivity. The institutions that efficiently and effectively conduct information in a market system are weak in the transitional environment. These may include formal and informal sanctioning for opportunistic behavior and false information, credible intermediaries, contracting and penalty provisions, trade associations and publications, and product catalogues, call centers, and other means of price dissemination. In terms of the model, the effect is again to relax the Inada condition so that the slope of the production function does not reach infinity as the capital stock drops as well as to lower the return to capital overall. While this and the above may seem like a radical departure from standard form, 
it should be remembered that the Inada conditions were contrived as a convenience to ensure model solutions, not as a reflection of reality. Whereas in other environments, they may not affect outcome, in the transitional case they do clash with reality.

3. Informal institution: Institutionalized corruption in an incentive incompatible system, i.e. poor corporate governance. This leads to lower returns to investors than could be expected given the level of capital and slope of the production function. A combination of managerial behaviors and low investor expectations support this phenomena.

4. Formal institution: Financial markets and intermediation are weak. Proxies for financial market development have been found through much of the literature to be correlated with growth. This is a first step. What ultimately counts is how certain institutional flaws translate into savings decisions, which then affect capital stock. The prevalence of pyramid schemes, other financial scams, bank failures, and inefficient intermediation lead to a low expected return on investment. The ultimate consequence is under-investment relative to the technical return on capital available in the economy. Financial systems are often and accurately considered to be part in an economy's institutional framework [Murrell, 2006]. They represent the emergent lattice of multiple institutions related to contracting and property rights across a set of actors and assets.

The first two factors affect the shape of the production function, and in particular keep the function from exhibiting infinite, or even very high, returns to capital as capital stocks drop. As discussed above, informal and formal institutions can complement each other in practice. Factors 3. and 4. both lead to poor financial intermediation and low expected returns. One acts through patterns of corrupt behavior and the other through institutions that either do not protect against that behavior or incentivize different behavior.

The model developed in the following pages looks at the possible effects of initial conditions and both formal and informal institutions in consumer and firm behavior during transition. The exhibition is recognized to be only a start in terms of understanding institutional dynamics.

Simulations are used in the analysis because in most cases no analytic solution exists due to the non- 
standard assumptions necessary to proximate the initial conditions and institutional environment outlined above. These include: time variance, the possibility of non-rational expectations formation and non-infinitely decreasing returns to scale, voting, and distortions in factor payment driven by subsidization. The simulations track the progress over time of key variables: capital accumulation, consumption, voting behavior, and returns to capital under different scenarios of microeconomic conditions and reform regimes.

\section{THE ECONOMY AND THE MODEL}

This section outlines a basic Ramsey type model with functional modifications made to reflect the institutional factors discussed above. The economy is described by a standard one sector real model in which a continuum of identical, infinitely lived agents maximize utility and profits by choosing optimal levels of saving and consumption in each period.

\section{Equilibrium in the Economy}

An equilibrium for this economy is a sequence of consumption bundles, capital stocks, wages and asset returns over two policy states:

$$
\left\{c_{t}\right\}_{t=0}^{\infty} \quad\left\{A_{t+1}\right\}_{t=0}^{\infty} \quad\left\{w_{t}^{p_{i}}\right\}_{t=0}^{\infty} \quad\left\{r_{t}^{p_{i}}\right\}_{t=0}^{\infty} i=1,2 . \text { states }
$$

such that each group of agents in the model solves their respective problems for each time period from $t=1$ to $\infty$. Respectively, $c_{t}$ and $A_{t}$ are the consumption choices and asset levels in each period $t$. Wages and returns to capital in each period $t$ and policy state $i, i=1,2$, for non-reform and reform states in the economy are denoted by $w_{t}^{P_{i}}$ and $r_{t}^{P_{i}}$. Economic reform enters the model in two ways. The first is through voting where voters choose one of two policy states, "non-reform" or "reform." The second type of economic reform occurs in the production structure of the economy and will be described in detail later. 


\section{Consumers' Problem (1): Consumption and Investment}

A continuum of consumers in the economy maximize the present value of their utility from consumption, where future wages and returns on assets are uncertain. Their joint problem is to maximize the time separable utility function:

$$
\text { Max: } V=\sum_{t=0}^{\infty} \beta^{t} u\left(c_{t}\right)
$$

subject to budgetary and non-negativity constraints:

$$
\begin{gathered}
c_{t}+A_{t+1}=\mathrm{E}\left[w_{t}^{p} \mid \Omega\right]+\left(\mathrm{E}\left[R_{t}^{p} \mid \Omega\right] A_{t}\right. \\
c_{t}, A_{t}, R_{t}^{p}, w_{t}^{p}, \pi_{t} \geq 0 \quad \forall t=1 \ldots \infty \\
\Omega=\Omega\left(R_{t-s}^{p}, w_{t-s}^{p}, \pi_{t}\right) \quad s=0 \ldots t
\end{gathered}
$$

where (suppressing the policy state notation) $w_{\mathrm{t}}$ is the wage paid to labor at time $\mathrm{t}$, and $R_{\mathrm{t}}$ is the gross return, $(1+r)$, that agents receive on the period's stock of loaned capital. The full information set available at time $\mathrm{t}$ is $\Omega$. The utility function is assumed increasing in consumption and strictly concave. There is only uncertainty on the consumer side of the economy, including future wages and returns on assets ${ }^{2}$. Assets are equivalent to the capital stock in the economy.

As will be discussed later, consumers can vote for reforms related to how wages and returns are generated. However, the random variable $(1-\pi)$ is the probability that the economy will follow reform rules in the next period, regardless of voter preference. Given pressure from international institutions and banks, uncertain elections, and reform in neighboring countries, consumers expect that reform will happen with some positive probability. They consider this probability of reform in their consumption and savings plans. In the pre-reform policy state, as $t \rightarrow \infty$ the probability of reform converges to and reaches one before a steady state is reached. In the reform policy state, the value of $\pi$ is equal to zero by default.

The next period's wages and return on capital, $R_{t+1}^{i}$ and $w_{t+1}^{i} i=1,2$, are generated deterministically on the production side of the model, but consumers view them with uncertainty. Since 
the transitional environment lacks stable time series, well understood policy effects, consumer experience, and is subject to unprecedented shocks, rational expectations is not assumed in the early stages of transition. Wages and returns to capital in any period depend upon the previous period's consumer consumption-savings decisions, whether reform has taken place or not, the level of capital in the economy, and the current shape of the production function. Uncertainty decreases as a steady state is reached in the post-reform policy state. Since the main purpose of the model is to account for uncertainty and dynamics during transition, there are no residual shocks or uncertainties once reaching the steady state. Credit rationing constrains consumer borrowing in the pre-reform policy state, so net assets are always positive. The model limits borrowing in the post reform policy state to avoid Ponzi schemes.

It is assumed for simplicity that agents possess a logarithmic utility function. Though high at unity, functions with a lower inter-temporal elasticity of substitution would only strengthen the results of the model. Solving directly for consumption yields the rule for any period t:

$$
c_{t}=(1-\beta)\left[\begin{array}{l}
w_{t}+A_{t}+\pi_{t} \mathrm{E}\left[R_{t}^{1,-1} w_{t+1}^{1}+R_{t}^{1,-1} R_{t+1}^{1,-1} w_{t+2}^{1}+\ldots+\varepsilon_{1}+\Theta^{1}\right] \\
+\left(1-\pi_{t}\right) \mathrm{E}\left[R_{t}^{2,-1} w_{t+1}^{2}+R_{t}^{2,-1} R_{t+1}^{2,-1} w_{t+2}^{2}+\ldots+\varepsilon_{2}+\Theta^{2}\right]
\end{array}\right]=\Phi
$$

where $\Theta$ is the residual, made up of the variance and covariance terms from factoring out a nonindependent expectation term, in this case the serially correlated returns. This unknown will render any derived consumption function useless for econometric estimation, but since the term is assumed constant in policy states, it will still yield comparable levels of relative consumption and savings behavior. The derivation is a straightforward permutation on that given for the basic model in Sargent [1987].

In each period, some proportion of assets and actual and expected wages is consumed. Consistent with permanent income and life cycle theories of consumption, the term to the right in equation (4) is the consumer's best estimate of permanent income given current information. ${ }^{3}$ The residual term is determined by the prevailing policy state. Since covariances differ depending on the 
policy state, the relative values of the residuals will differ as well. Since the covariance between the variables is assumed constant over time the residuals are time invariant. The term $\varepsilon_{i} \quad i=1,2$ is some remainder greater than zero which is estimated in the simulations.

As shown in equation (4), in the non-reform state consumers base their consumption decisions upon expected wages and returns in a weighted combination of pre-reform and post-reform states. The expected probability of reform in the next period is $(1-\pi)$, where $\pi$ is:

$$
\pi=\lambda e^{-\lambda(t-1) / c}
$$

and $c$ is a constant governing the anticipated rate of reform. When $c=18$, the function $(1-\pi)$ changes with $\mathrm{t}$ as shown in Figure 1 below.

Figure I

Consumers in the simulations make their consumption decisions in any period based upon equation (4) above. Expected values are generated for ten periods into the future and remainders for the infinite series are numerically estimated to the limit. The expectations generating routine used is a combination of naïve, function-based forecasts and an exponential smoothing rule. The naïve model extrapolates on the existing, current period function and uses the wage return rules for the relevant policy state to generate expectations. Exponential smoothing is used for forecasts in the region of the production function after the inflection point. Consumer behavior after the resolution of uncertainty converges to that of the most basic models [Sargent, 1987] with stable wages and returns, or:

$$
c_{t}=(1-\beta)\left[A_{t}+w\left(\frac{R}{R-1}\right)\right] \mid
$$


Population preferences are an important element in any major reform. Though more important in democratic countries, autocratic rulers still depend on popular support to varying degrees.

Introducing voting into the model helps capture this additional factor that has often had a major impact on the direction of reforms. Using a basic search and optimization model, voters choose one of two policies in each time period. In the pre-reform state, subsidies are given to state industry leading to higher wages and lower returns on investment. In the post-reform state wages and returns are in line with their marginal products. This depiction is consistent with the observation that wages in private companies were lower than those in public companies during the initial period of reform [Aghion and Blanchard, 1994]. The wage disparity is one of the main reasons for resistance to reform and restructuring, with support for reform waiting until the majority believes ex ante in the benefits of reform ex post [Dewatripont and Roland, 1995]. In voting, consumers seek to maximize the discounted expected value of real lifetime wages. Whereas total returns are used in the consumption and investment problem above, wages are used in the voting problem since salaries and employment were main concerns of voters at the inception of and during transition.

$$
\underset{p_{1}, p_{2}}{\operatorname{Max} V}=\mathrm{E}\left[\sum_{t=0}^{\infty} \beta^{t} u\left(w_{t}^{P_{i}}\right) \Omega\right]
$$

Wages and returns to capital become a function of the policy state, as shown in the third and fourth terms in equation (1). The rationale will be explained in the section below. In general:

- $\mathrm{E}\left[w_{t+1}^{1} \mid p=1\right\rfloor \mathrm{E}\left[w_{t+1}^{2} \mid p=1\right\rfloor$ The expected value of the next period's wage is greater in the prereform state than in the post-reform state.

- $\mathrm{E}\left[R_{t+1}^{2} \mid p=1\right\rfloor \mathrm{E}\left[R_{t+1}^{1} \mid p=1\right\rfloor$ The expected real return on assets is greater in the post-reform state than in the pre-reform state.

\section{Firms' Problem}

The firms' problem accounts for two changes to accommodate the four factors discussed above. First, in the pre-reform policy state it is not assumed that firms pay factor costs according to competitive criteria. This is for the reasons discussed above and because political factors force a high 
wage/employment bill, leaving less for returns to capital. Wages are less flexible than capital returns in economies with strong workers groups, but soft budget constraints and weak financial intermediation. In sum, firms in the pre-reform policy state do not satisfy the standard competitive cost minimization conditions:

$$
f_{k}(k, 1)=r_{t}+\delta \quad f_{l}(k, 1)=w_{t}
$$

where $\delta$ is the rate of capital depreciation. Rather in the pre-reform policy state,

$$
f_{l}(k, 1) \neq \text { paid wage, but wage }=w_{t}^{1}
$$

while the remainder of the product goes to payments to capital. In the post-reform policy state, labor and capital are paid their marginal products as in (7). There are zero net profits under either policy state.

Though subsidization takes place, there is no explicit role for government in the model. All wage subsidization occurs implicitly within the firm and balances in a single time period through an implicit tax on capital. By increasing wages, the returns firms can pay to capital are lessened, leaving both lower actual returns for the current period and forecasted returns in the consumers' consumption/ saving problem. The share of consumption in GDP under central planning was known to be low. However, once transition began, private consumption increased as a share of GDP, as investment declined [Fischer and Sahay, 1999]. Production also decreased, in line with the "disorganized" environment of Blanchard and Kremer [1997], as the existing capital stock became unable to generate product under the new institutional environment. This shift from high levels of capital and production, to a huge capital stock neutered by the new environment is instrumental in the dynamics of transition. As reflected in the model, in many cases, wages soon outstripped the ability of firms to produce, leading to subsidization.

The second departure from the standard model is in the returns to capital. It is generally assumed that production functions satisfy the Inada conditions. However, for the reasons discussed above firms in the early stages of reform are given a return function with the qualities: 


$$
f_{k k}(k) \equiv\left\{\begin{array}{l}
>0 \text { for } k \in(0, \widetilde{k}) \\
\leq 0 \text { for } k \in(\widetilde{k}, \infty)
\end{array}\right\}
$$

The marginal productivity of capital goes through a period of non-decreasing returns at low levels of capital. The function becomes a standard decreasing function in the range after the capital stock $\hat{k}$ has been achieved, but never reaches a point of infinite returns at any level of capital. The results is that there is no guarantee that at some point, returns to capital will be high enough to entice investors to forego consumption in the current period. The functional form used in the simulations is:

$$
f(k, 1)=c_{t} * k^{g(k)}=1+\frac{t}{3 * t^{\cdot 4}} \cdot 7 k^{\frac{1}{2-1.5(\operatorname{EXP}(-.05 *(k+1) / 2) * t / r a t e))}} .
$$

The function can be set to change with increases in $t$ to a strictly concave form. At low levels of $t$, or early in transition, the production function goes from non-strictly concave to strictly concave in $k$. The maximum return to capital is at the inflection point. As $t \rightarrow \infty$ the functional form converges to a strictly concave function satisfying the Inada Conditions. The maximum return to capital at $t=0$, or prior to any production function reform, is around 60 percent. This is consistent with the target rates of return sought out by early stage investors in economies in transition. Adjustments are made in the simulations for pace of reform and period of initiation under different scenarios. The default settings begin reform at $t=10$ and terminate it at $t=24$, giving 14 time periods of convergence. The functional form is shown in Figure 2 for three values of $t$. The speed of reform may also be adjusted in the simulations with the function's "rate" variable.

\section{Figure II}

In the model, each set of agents solves their respective problems in each time period. The result of these solutions determines the capital stock, policy state and actual and expected returns in the next period. The process is carried out from time period $t=1$ to $\mathrm{T}$, or to convergence to a steady state. 


\section{Changes in Capital Stock}

Capital stock changes in the economy according to the familiar relationship:

$$
k_{t+1}-k_{t}=f\left(k_{t}\right)-\delta k_{t}-[\Phi]
$$

The last term is equation (4) from the consumers' choice problem. Capital accumulation is governed directly by the solution to the consumers' saving and investment problem. Evolution of the capital stock depends entirely upon known terms and expectations based on known terms.

\section{Financial Intermediation}

As discussed above, the transitional environment can harbor formal and informal institutional factors which drive inefficiencies in financial intermediation. The model has a variable which modifies the realized and forecasted returns on capital according to the hypothesized state of the financial sector. This parameter allows the model to explore the effects of an underdeveloped or insecure system of financial intermediation. Real returns will be $\theta_{t} R_{t}^{P_{i}}, \theta_{t} \in[0,1]$, where $R_{t}^{P_{i}}$ is the total return $\left(1+r_{t}^{P_{i}}\right)$ at time $t$ and policy state $i$. In the simulations, the default value of $\theta$ is 1 , or no inefficiencies.

\section{Depreciation and Capital Depletion}

In the model, capital is depleted only through depreciation. Though asset stripping may have been prevalent in reality, in a closed model those assets would be deployed elsewhere. The model is, however, devised to account for different rates of depreciation under the two policy states. In the prereform state, depreciation can be made higher than under private ownership when capital is more valued and paid its marginal product. The model results do not depend upon this assumption and the default values in the simulations are that the two rates are identical.

\section{Economic Efficiency}


As noted in the discussion above, poor protection of property rights and management can cause economic loses in firms. On this basis, a parameter setting on the model makes a purely ad hoc adjustment to economic efficiency between the policy states. The parameter does not affect productivity, of the level of output for a given input level, but adjusts the sum of returns paid to labor and lenders as opposed to the actual output of the firm. Though on a technical level firms may be operating reasonably efficiently, there may be waste and/or theft at the input and output levels, leaving a lower level of payments to wages and capital than would be the case under stricter controls. Again, the treatment is ad hoc but reflects observations. The default parameter in the model is that there is no such loss and results do not depend upon it.

\section{SIMULATIONS ON THE MODEL}

A routine was written using Mathematica to run simulations on the model with the functional forms described above. The default parameters are those of a standard neoclassical growth model. Parameters can then be changed and the model run under a range of assumptions designed to emulate the particular initial conditions and institutional characteristics at the onset of and during transition.

The simulations begin with a given capital stock, policy state and production structure at $t=1$. According to the equations described above, wages, returns and expectations are generated for that period. Consumers solve their problems using these variables. This determines the capital stock and policy state for $t=2$ and so on. The following default assumptions and model parameters hold for all of the simulations unless otherwise stated.

- Depreciation of 12 percent and identical in the two policy states.

- Discount factor, $\rho=.11$, or $\beta=.90$.

- Fully efficient financial intermediation, i.e. returns to capital identical to realized and expected returns to investors.

- Begins in policy state 1 .

- Beginning capital level 1.5.

- No downward adjustment for lower efficiency and wasted subsidies in policy state 1 as opposed to policy state 2 .

- Production function "S" shaped at early stages of reform. Amount of production function reform to neoclassical form is variable, ranging form fully reformed to no reform.

- Simulations continue for 30 time periods. 
Output for the simulations is presented graphically. Levels of variables tracked are recorded on the vertical axis with time on the horizontal axis. The variable labeled "policy" on the vertical axis gives a value of 1 if the non-reform policy state prevails at the time and 2 if the reform state prevails. The figure marked "accumulation" shows the net increase or decrease in capital in any time period.

\section{Scenario 1: Standard Model}

\section{Figure III}

This example shows the transition dynamics when neoclassical assumptions hold in the economy. The economy has a low capital stock, but the underlying structure is in line with the standard assumptions, i.e. strictly concave production function, factors are paid their marginal products as a result of cost minimization (policy state 2 prevails throughout), Inada conditions hold and financial intermediation is efficient.

As can be seen from Figure 3, the transition dynamics are smooth and a steady state is quickly achieved. Wages and consumption rise together. As is to be expected, the rate of capital increase is highest where returns to capital are highest. Under the standard competitive market assumptions, transition occurs smoothly under the post-reform policy state. This is a standard and expected result. The remaining simulations show the deviation from this base model when assumptions are changed to reflect the different initial conditions and institutional deficits.

\section{Scenario 2: Institutional Failure}

Figure IV

In this scenario, all of the initial conditions and institutional failures discussed above are introduced. Though such a situation has not been the norm and in most cases has not persisted over time, it is illustrative of where many economies started. The combination of a non-neoclassical production structure, firm subsidies, poor financial intermediation, inefficiency, low expectations for 
improvement, and high physical depreciation of assets has reflected reality at some point for almost all economies in transition. Many such as those in the North-Western part of the region and later the Balkans have moved beyond this situation. However, even fifteen years later, others such as the Ukraine, Moldova and much of the CIS have either only recently emerged or remain mired in similar conditions. The scenario illustrates how optimal consumption decisions coupled with institutional problems in the micro-economy can lead to capital depletion, rather than accumulation. Assumptions:

- No production reform. Production function is as $\mathrm{t}=1$ in Figure 2.

- Weakness in the banking sector maintains positive expected real interest rates, but inefficiency in intermediation leads to returns half those payable as interest by firms.

- Low expectation of forced reform in the next period.

- Production inefficiency, corruption and skimming drive a wedge between actual and paid returns to capital, in addition to capital flight, lead to of 25 percent of firm production not reaching factor payments.

- Depreciation rate increased to 14 percent due to poor stewardship.

Figure 4 shows the economy caught in a cycle of political instability and initially decreasing and then low and unstable capital and consumption. Though parameters were set at fairly extreme levels, results are reasonably robust to parameter changes. When voting is not allowed and the nonreform policy state is enforced the result is similar, but without the cycles of political instability. The capital stock, consumption and wages simply decline over time to a low steady state. The political instability in the model is driven by a perceived need for reform in the non-reform state. However, consumers will not accept the initially lower wages and consumption which results, leading to policy reversal.

The persistent lack of accumulation is due to the inability of the production and financial sides of the economy to generate sufficient real expected returns to entice consumers to forego current period consumption. In reality, this low capital "trap" is unlikely to continue forever. A number of events can break the cycle and bring about some, at least moderate, capital accumulation. These include: production reform, banking reform, a rise in expectations, increased efficiency or productivity, or in many cases reform imposed by outside creditors.

In most of the former Soviet Union, Bulgaria, Romania and the Ukraine, economies were at least initially caught in cycles of political instability, capital depletion and lowering consumption 
levels. The political pattern has often been to and from reform governments, as indicated in the model. For Bulgaria, it was seven years after the beginning of transition that political instability and complete bankruptcy of the state brought a combination of an elected reform government and reform under pressure from the International Monetary Fund and World Bank. As of mid-2007, the Ukraine, Moldova and much of the CIS had not initiated credible reform and were still stuck in a low capital and even depleting situation. Ukraine may have a chance to break the cycle, but indications are mixed. In several cases in the CIS, the pattern was broken more recently by external factors, or high natural resource prices. At this level of simplicity, it is not possible to see from the model if a temporary oil shock can permanently move the economies into a cycle of accumulation. Given the current level of development of the model, should natural resource prices drop without undertaking basic institutional reforms, the cycle of capital depletion could begin again.

\section{Scenario 3: Standard Assumptions and Economic Reform}

\section{$\underline{\text { Figure V }}$}

Clearly a number of transitional economies have been able to pass through the main hardships of transition fairly quickly. These include many of the nations in the North-Western corner of Central and Eastern Europe such as Poland, Hungary, the Czech Republic, and the Baltic states. These countries started the transition with either more developed market institutions or more fertile ground for their introduction, different initial conditions, greater expectations of reform, perhaps due to their proximity to the West, and probably less inherent inefficiency in the financial sector. This simulation looks at the effects of this relatively more developed set of institutions on the process and speed of reform.

In this example, basic institutions in the micro-economy improve with the process of reform. Production reform begins, the banking sector improves with time, and efficiency increases. Assumptions:

- Production reform begins after period 12. 
- Losses in financial intermediation decrease from 30 percent in the first policy state to 10 percent in the second policy state.

- Expectation of imposed reform returns to default values.

- Efficiency loss disappears in second policy state with privatization and rationalization.

Figure 5 shows an initial period of capital depletion until the onset of production reform in period 12. After period 12, the production function takes on a more standard, concave shape and returns at low capital levels increase, enticing consumers to save. Period 12 is also followed by a short period of political reform and some moderate capital accumulation. In period 20, voters choose more comprehensive reform and after a short and moderate shock to wages and a larger decrease in consumption as agents increase saving, capital accumulation accelerates along with wages and consumption. It shortly thereafter reaches a somewhat unstable steady state. This oscillatory behavior in this case is driven by the expectations generating algorithm in the program. With a smoothing mechanism, the steady state would be more stable. It is not, however, inconsistent with observations.

The simulation shows the effects of a combination of structural and institutional and policy reforms in a transitional economy. When these elements work together, the results are favorable. The model results are quite robust with small deviations in the basic parameters also only producing small deviations in the outputs. The results of simulation 1 show the transition path under perfect neoclassical conditions. However, both in terms of the model and what has been observed, economies are more likely to follow a path such as the one shown in this simulation. Though certain reform policies may make some unrealistic assumptions about the underlying institutional state of nonmarket economies, given non-pathological initial conditions and some convergence to these institutional ideals, positive results can be expected. The model indicates that policy reform without first putting institutions in place (as in the "big bang" programs) can be a reasonable default paradigm under fairly wide ranging conditions.

\section{Scenario 4: Failure of Reform Under Institutional Weakness}

\section{Figure VI}


This simulation shows results when prices are rationalized and subsidies ended without concurrent microeconomic and institutional reform. Assumptions:

- Policy state 2 imposed throughout, so factors are paid their marginal products.

- Banking failure. Returns to investors are lower than those paid by firms for capital.

- No Production reform

- Default expectations of reform

Figure 6 shows a depletion of capital. Even though consumers are making "rational" consumption decisions and factors are being paid their marginal products, capital is consumed rather than saved and the economy is caught in a low capital steady state. As capital drops, so does production and funds available for investment in the future. Given some basic changes in assumptions, but still within the range of what is believable, reform on its own can lead to capital depletion. Caught in a trap below the inflection point, the production and banking side cannot generate the expected returns to entice consumers to forego consumption and invest in the current period. The level of capital depletion is actually greater than when the reform policy state is not imposed throughout the simulation (see Scenario 2. above). Under pathological conditions, imposed reform may not generate better results than total lack of reform.

There is a wide range of combinations of capital starting points, expectations of externally imposed reform and levels of financial sector failure which generate the same basic results. If returns are not high enough to propel savings at the onset or transition, the economy sinks into a low capital trap. The further capital drops, the more difficult it becomes to rescue the economy, requiring more real economy reforms and improved institutions to break the cycle.

The model is restricted to offering non-negative real returns to capital, though negative returns have in-fact prevailed for periods of time in a number of transitional economies including the Russian Republic, Bulgaria and Poland during the early years of transition. Changing the model to account for negative returns to capital would require making some modifications in the program to force convergence when estimating equations. However, the final effect would be to compound the results already recorded here. As has occurred, when consumers are faced with the prospect of saving 
at a negative rate or holding consumption goods or hard currency at a neutral rate, they have chosen the latter.

\section{CONCLUSIONS AND EXTENSIONS}

The analysis and model support recent empirical analyses in that for similar policy regimes, institutions and initial conditions may have a significant effect on how those policies ultimately affect the economy. Perhaps an unsurprising result from the simulations is that the more developed (in market terms) the underlying micro and institutional structure, the better the probability of voting for reform as well as the economy's response to reform, either voted for or imposed. Institutions and initial conditions both effect growth directly and play dynamically into the set of conditions that an economy faces at the next stage. The simulations start to show the dynamic nature of the affects of these factors in a way that econometric studies cannot.

The ultimate reconciliation of neoinstitutional and neoclassical concepts of growth will be a major challenge of the coming decade. Theory and evidence indicates that there is no ignoring either. This is especially true for transitional and emerging markets, where the full set of market-supporting institutions may be lacking. Formulating good policy will require an understanding of the full spectrum of institutional capability in a particular economy. 


\section{$\underline{\text { Notes }}$}

1. Since explicit measurement of broad institutional change and development is problematic, authors have used a number of proxy indicators. These include: indices of restructuring and governance, and indicators of quality of local government, executive accountability, law enforcement, property rights enforcement, and extent of civic organizations.

2. Constant variance and covariances within states are assumed. Since only relative levels of consumption and savings are relevant in the analysis, simulation results are not affected.

3. There are considerable problems in deriving theoretically consistent, i.e. derived from utility maximization, analytic solutions to consumption functions under uncertainty. The literature is full of both highly restricted forms as well as sophisticated numerical techniques to get around these problems. These studies have been mainly concerned with fitting the forms to data. The purpose of this study is to look at relative changes in consumption and savings so a complete analytic solution is not necessary. 


\section{Bibliography}

Acemoglu, Daron and James Robinson "The Role of Institutions in Growth and Development," Working Paper No. 10, Commission on Growth and Development, 2008

Aghion Philippe and Olivier Jean Blanchard "On the Speed of Transition in Central Europe" NBER Working Paper No. 4736, May 1994.

Aixalá José and Gema Fabro "Does the Impact of Institutional Quality on Economic Growth Depent on the Initial Income Level?" 2008 Economic Affairs 28 (3): 45 - 49.

Bardhan, Pranab “Institutions matter, but which ones?” Economics of Transition 2005 13(3): 499-532.

Bhaumika, Sumon Kumar and Saul Estrin "How Transition Paths Differ: Enterprise Performance in Russia and China," 2007 Journal of Development Economics 82 (2): 374-392

Beck, Thorsten and Luc Laeven "Institution Building and Growth in Transition Economies" Journal of Economic Growth 2006 11: 157-186

Barro, Robert J. and Xavier Sala-i-Martin Economic Growth: Second Edition Cambridge: The MIT Press, 2005.

Blanchard, Olivier and Michael Kremer "Disorganization" Quarterly Journal of Economics 1997 Vol CXII (4) November: $1091-1126$.

Campos, Nauro F. and Fabrizio Coricelli, "Growth in Transition: What We Know, What We Don't and What We Should” Journal of Economic Literature 200240 September: 793 - 836.

Beck, Thorsten and Luc Laeven "Institution Building and Growth in Transition Economies" World Bank Policy Research Working Paper 3657, July 2005

Berg, Andrew, Eduardo Borensztein, Ratna Sahay and Jeromin Zettelmeyer "The Evolution of Output in Transition Economies: Explaining the Differences” IMF Working Paper 99/73, 1999.

Bromley, Daniel W. "Reconstituting Economic Systems: Institutions and National Economic Development" Development Policy Review 1993, 2: 131-151.

Chousa, Juan Piñeiro, Haider A. Khan, Davit Melikyan, Artur Tamazian “Assessing Institutional Efficiency, Growth and Integration Emerging Markets Review 2005 6: 69- 84.

De Melo, Martha, Cevdet Denizer, and Alan Gelb "Patterns of Transition from Plan to Market," 1996 World Bank Economic Review 10 (3): 397-424.

De Melo, Martha, Cevdet Denizer, Alan Gelb and Stoyan Tenev, "Circumstance and Choice: The Role of Initial Conditions and Policies in Transition Economies," 1997, World Bank Policy Research Paper, The World Bank.

Dewatripont, Mathias and Gerard Roland "The Design of Reform Packages Under Uncertainty" American Economic Review 85(1995): 1207-1223.

Dixit, Avinash K Lawlessness and Economics: Alternative Modes of Governance Princeton University 
Press: Princeton, 2004.

Falcetti, Elisabetta, Martin Raiser and Peter Sanfey "Defying the Odds?: Initial Conditions, Reforms and Growth in the First Decade in Transition" Journal of Comparative Economics 2002, 30 (2): 229 250 .

Falcettia Elisabetta, Tatiana Lysenkoa and Peter Sanfey "Reforms and Growth in Transition: Reexamining the Evidence" 2006, Journal of Comparative Economics 34 (30): 421-445.

Fischer, Stanley, Ratna Sahay, Carlos A. Vegh "Stabilization and Growth in Transition Economies: The Early Experience" Journal of Economic Perspectives 1996 10(2): 45-66.

Fischer, Stanley, Ratna Sahay “The Transition Economies After Ten Years" Draft for a Conference Presentation, October 12, 1999.

Fischer, Stanley and Ratna Sahay "The Transition Economies After Ten Years" National Bureau of Economic Research Working Paper 7664, April 2000

Frydman, Roman and Andrzej Rapaczynski, Privatization in Eastern Europe: Is the State Withering Away? Central European University Press, 1994

Godoy, Sergio and Joseph E. Stiglitz "Growth, Initial Conditions, Law and Speed of Privatization in Transition Countries: 11 Years Later." National Bureau of Economic Research, 2006 Working Paper 11992.

Greif, Avner and Eugene Kandel, "Contract Enforcement Institutions: Historical Perspective and Current Status in Russia" IRIS Working Paper 92. Center for Institutional Reform and the Informal Sector. November, 1993.

Grogan, Louise, and Luc Moers, 2001, "Growth Empirics with Institutional Measures for Transition Countries," Economic Systems 28, 1-22.

Havrylyshyn, Oleh "Recovery and Growth in Transition: A Decade of Evidence" IMF Staff Papers Vol. 48, 2001.

Havrylyshyn, Oleh and Ron Van Rooden, "Institutions Matter in Transition, But So Do Policies" Comparative Economic Studies 2003 45: 2 - 24.

Heybey, Berta and Peter Murell "The Relationship Between Economic Growth and the Speed of Liberalization During Transition" Policy Reform 1998 Vol. 3: 121 - 137.

Kolodko, Grzegorz "Ten Years of Postsocialist Transition: the Lessons for Policy Reforms" The World Bank, Washington DC, 1999.

Krueger, Gary, and Marek Ciolko (1998), "A Note on Initial Conditions and Liberalization during Transition," Journal of Comparative Economics 26, 718-734.

Linn, Johannes F. "Ten Years of Transition in Central Europe and the Former Soviet Union: The Good News and the Not-So-Good News" in Transition: The First Decade edited by Mario I. Blejer and Marko Skreb MIT Press: Cambridge, 2002. 
Marangos, John "A Political Economy Approach to the Neoclassical Model of Transition" American Journal Of Economics and Sociology 2002 61(1): 259 - 276.

Murrell, Peter and Yijiang Wang, "When Privatization Should Be Delayed: The Effect of Communist Legacies on Organizational and Institutional Reforms." Journal of Comparative Economics 17(1993): 385-406.

Murrell, Peter "Institutions and Transition" Prepared for The New Palgrave Dictionary of Economics, 2nd Edition May, 2006 draft

North, Douglass Institutions, Institutional Change and Economic Performance Cambridge University Press: Cambridge, 1990.

North, Douglass Understanding the Process of Economic Change Princeton University Press: Princeton, 2005.

Radulescu, Roxana and David Barlow "The Relationship Between Policies and Growth in Transition Countries. Economics of Transition 2002 10(3): 719 - 745.

Redek, Tjaša and Andrej Sušjan "The Impact of Institutions on Economic Growth: The Case of Transition Economies" Journal of Economic Issues 2005 Vol. XXXIX (4): 995 - 1027.

Rodrik, Dani, Arvind Subramanian and Francesco Trebbi "Institutions Rule: The Primacy of Institutions Over Geography and Integration in Economic Development" Journal of Economic Growth 2004 9(2): 131-165.

Rodrik, Dani “Why We Learn Nothing from Regressing Economic Growth on Policies" 2005, Harvard University Monograph.

Rzonca Andrzej and Piotr Cizkowicz "A Comment on the Relationship between Policies and Growth in Transition Countries" Economics of Transition Volume 11 (4) 2003: 743-748.

Sargent, Thomas Dynamic Macroeconomic Theory Cambridge: Harvard University Press, 1987.

Schmieding, Holger, "From Plan to Market: On the Nature of the Transformation Crisis,"

Weltwirtschaftliches Archiv (127) 1993: 216-253.

Schenk, Karl-Ernst, "The Economic Policy Framework in Transition: Resistance to and Strategy for Change in Eastern Europe" Journal of Institutional and Theoretical Economics 148(1992): 103-115.

Selowsky, Marcelo and Ricardo Martin "Policy Performance and Output Growth in the Transitional Economies" American Economic Review 87-2 (1997): 349-353.

Svejnar, Jan "Transition Economies: Performance and Challenges" Journal of Economic Perspectives 2002 16(1): 3-28

Wang, Yijiang, Eastern Europe and China: Institutional Development as a Resource Allocation Problem China Economic Review vol. 4(1993): 37-47.

Williamson, Oliver The Economic Institutions of Capitalism New York: Free Press, 1985.

Yavlinsky, Grigory and Serguey Braguinsky, "The Inefficiency of Laissez-Faire in Russia: Hysteresis 
Effects and the Need for Policy Led Transformation." Journal of Comparative Economics 19(1994): 88-116. 
Figure Titles

Figure I: Expectation of Reform

Figure II: The Production Function Over Time

Figure III: Simulation Results 1

Figure IV: Simulation Results 2

Figure V: Simulation Results 3

Figure VI: Simulation Results 4

Figure VII: Simulation Results 5 
Figure I

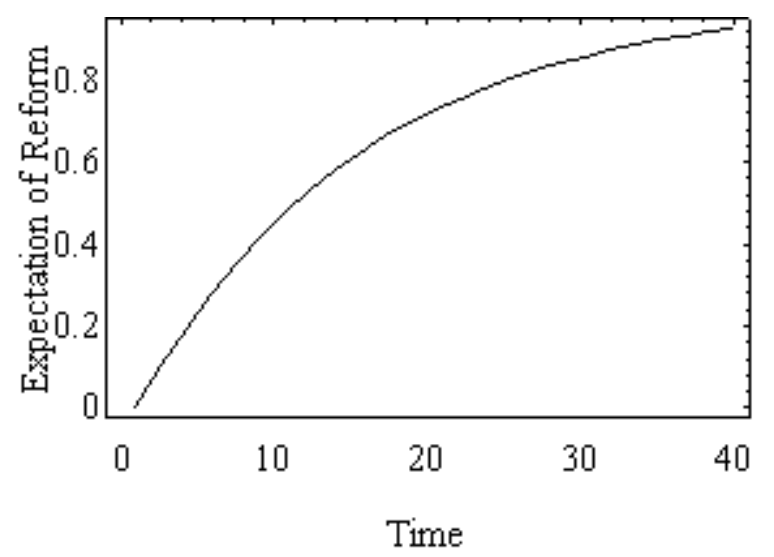


Figure II

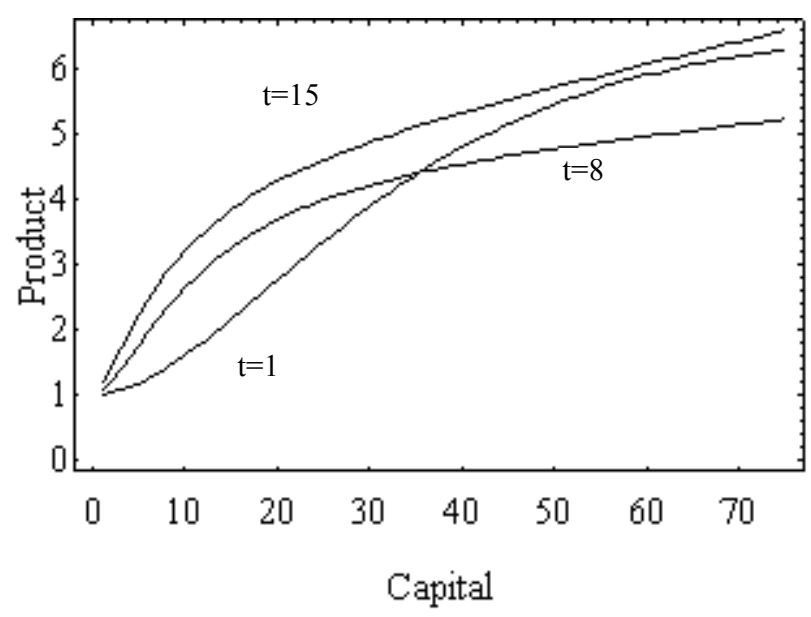


Figure III
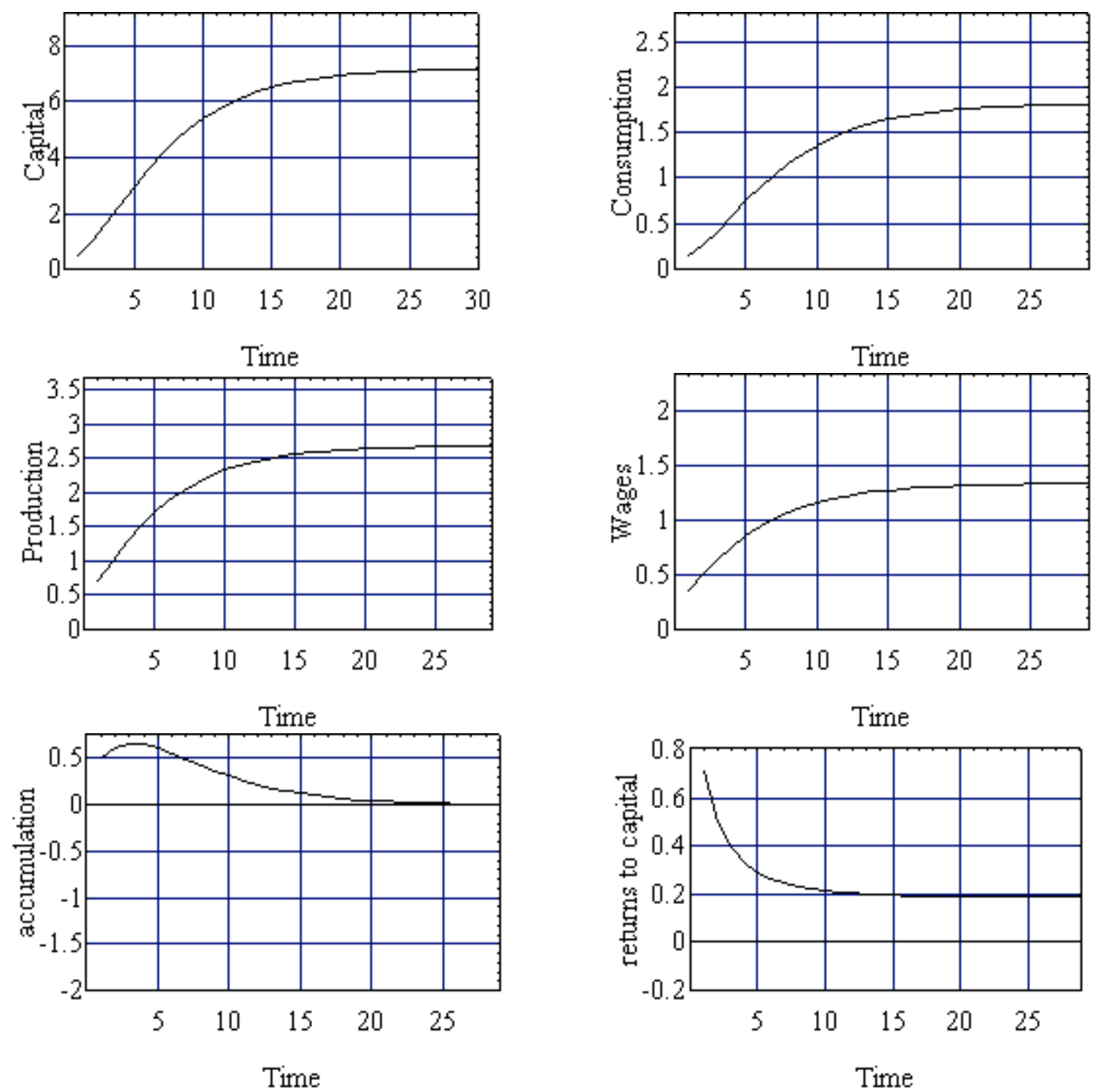

Phase Diagram

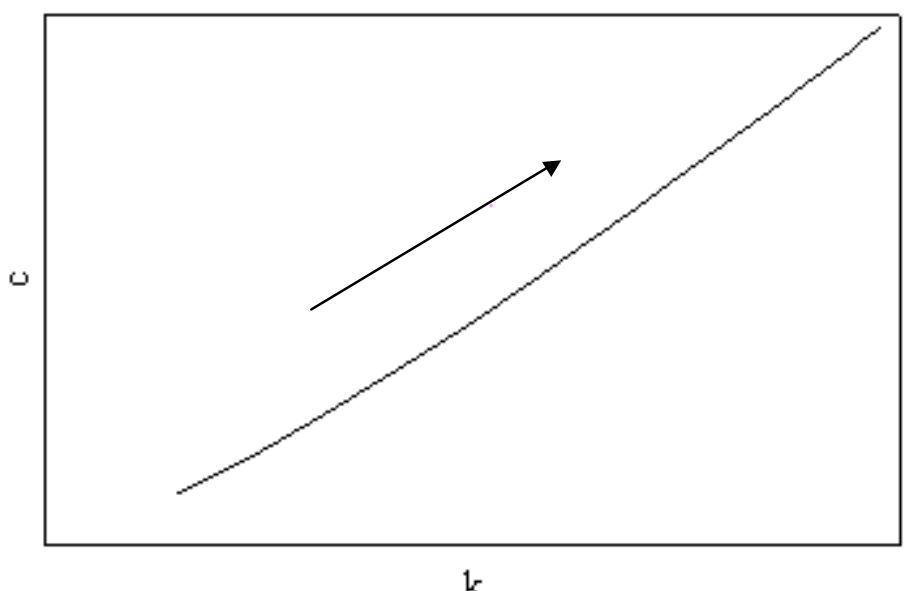


Figure IV:
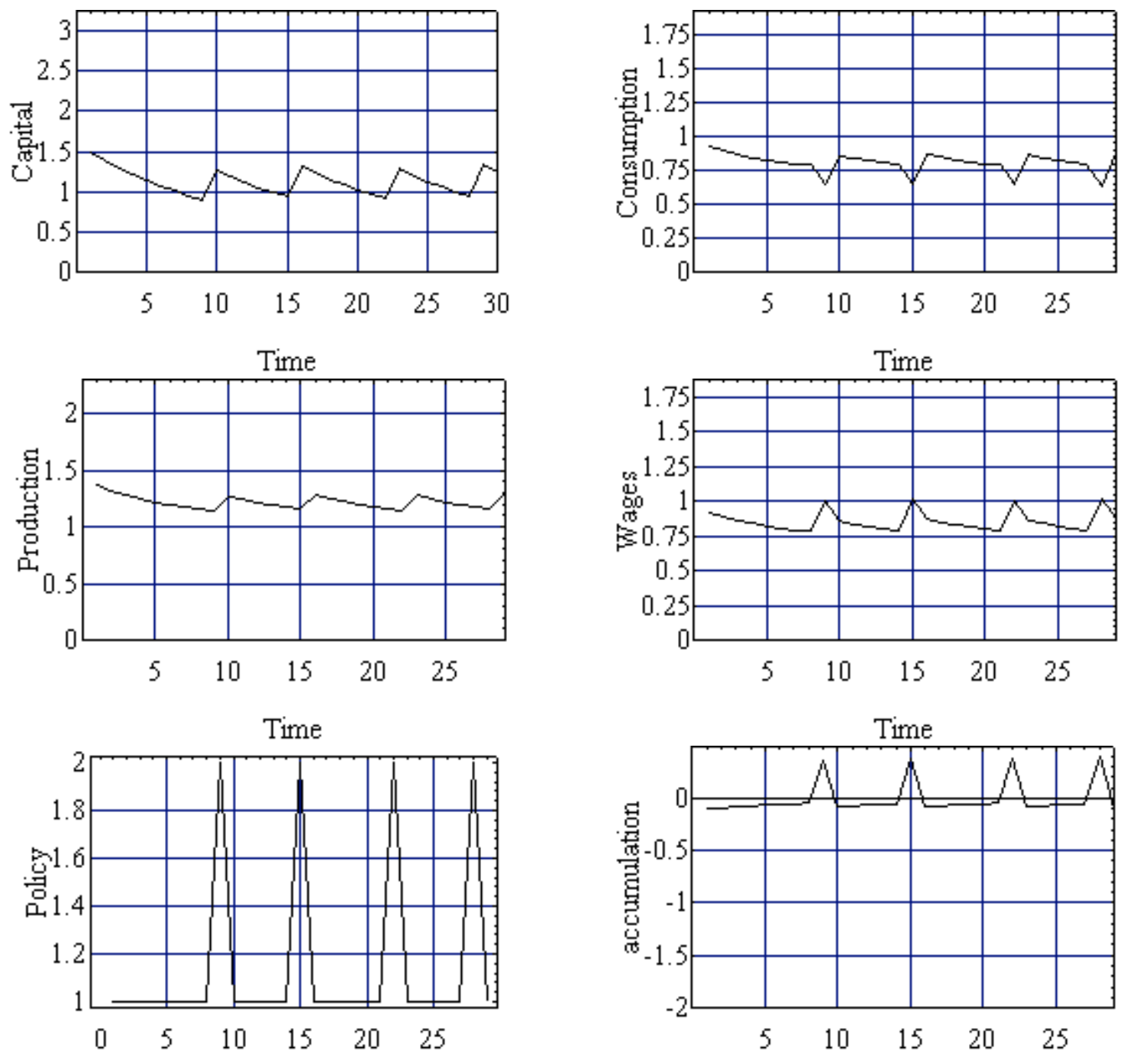

Time

Time

Phase Diagram

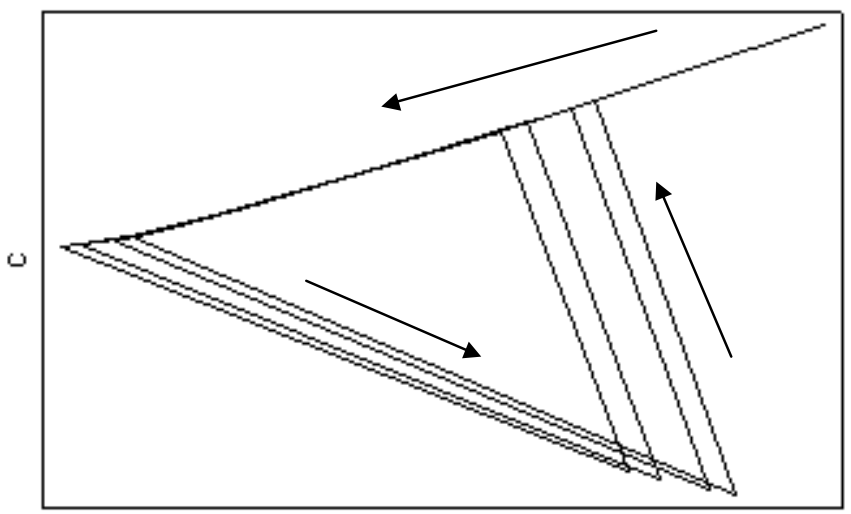

k 
Figure V:
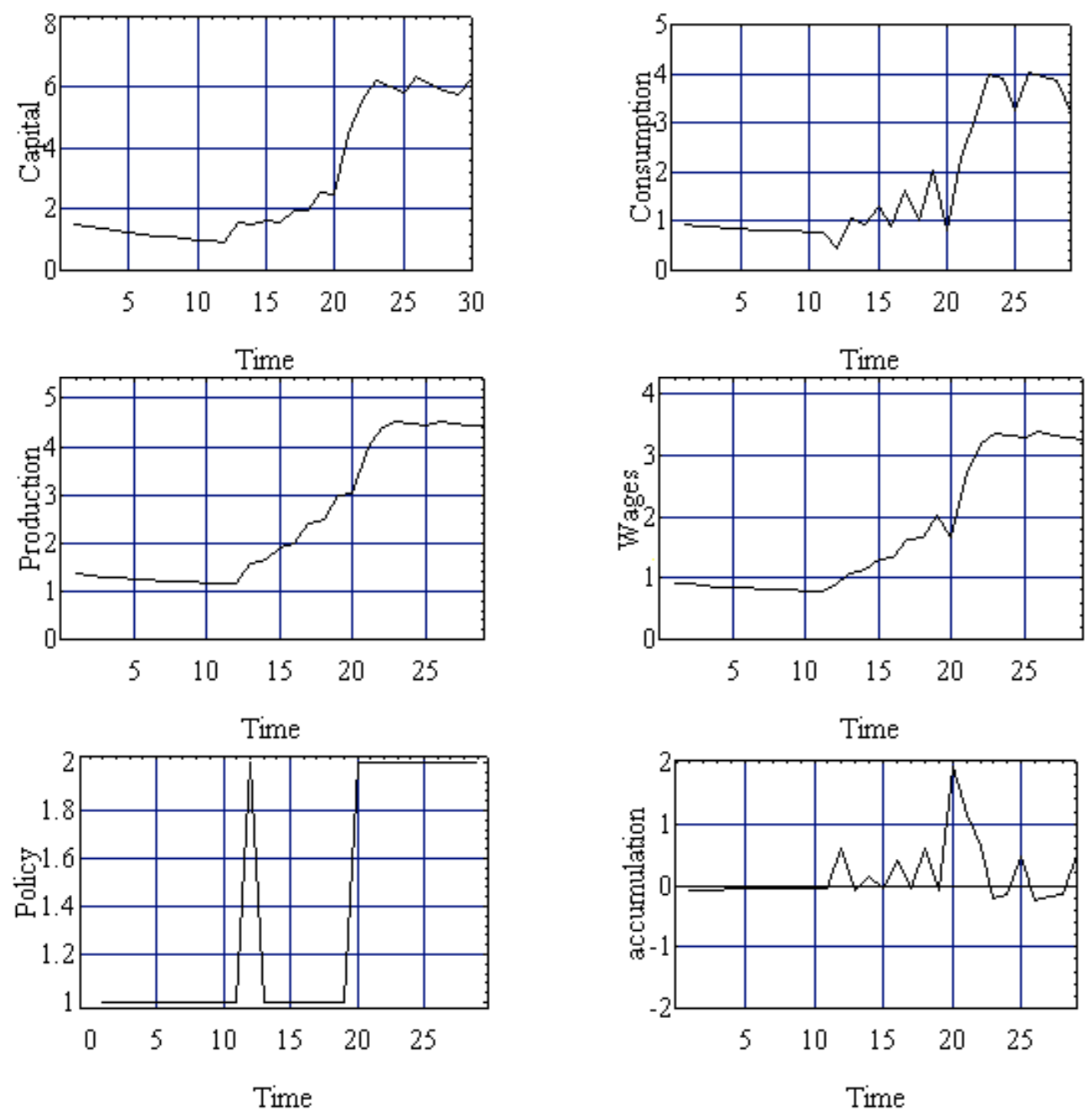

Phase Diagram

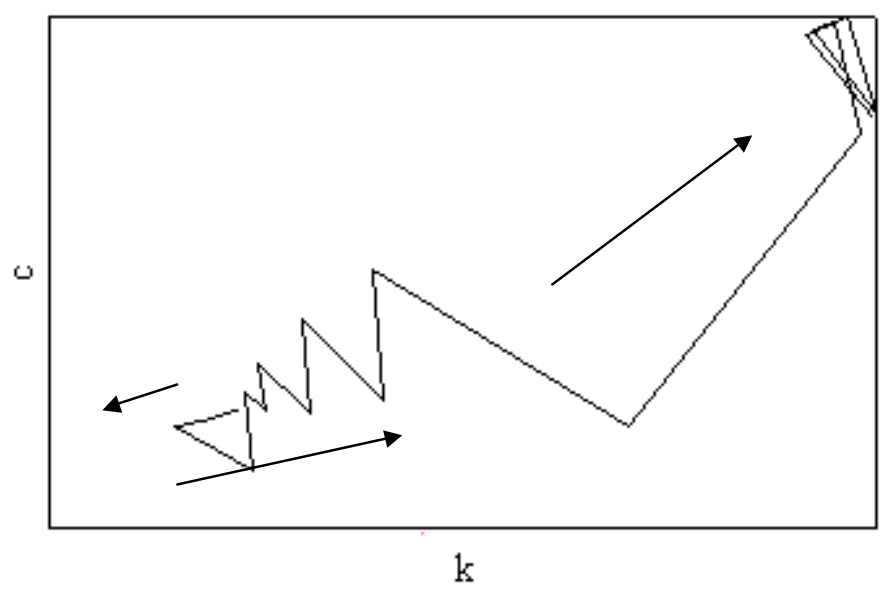


Figure VI:
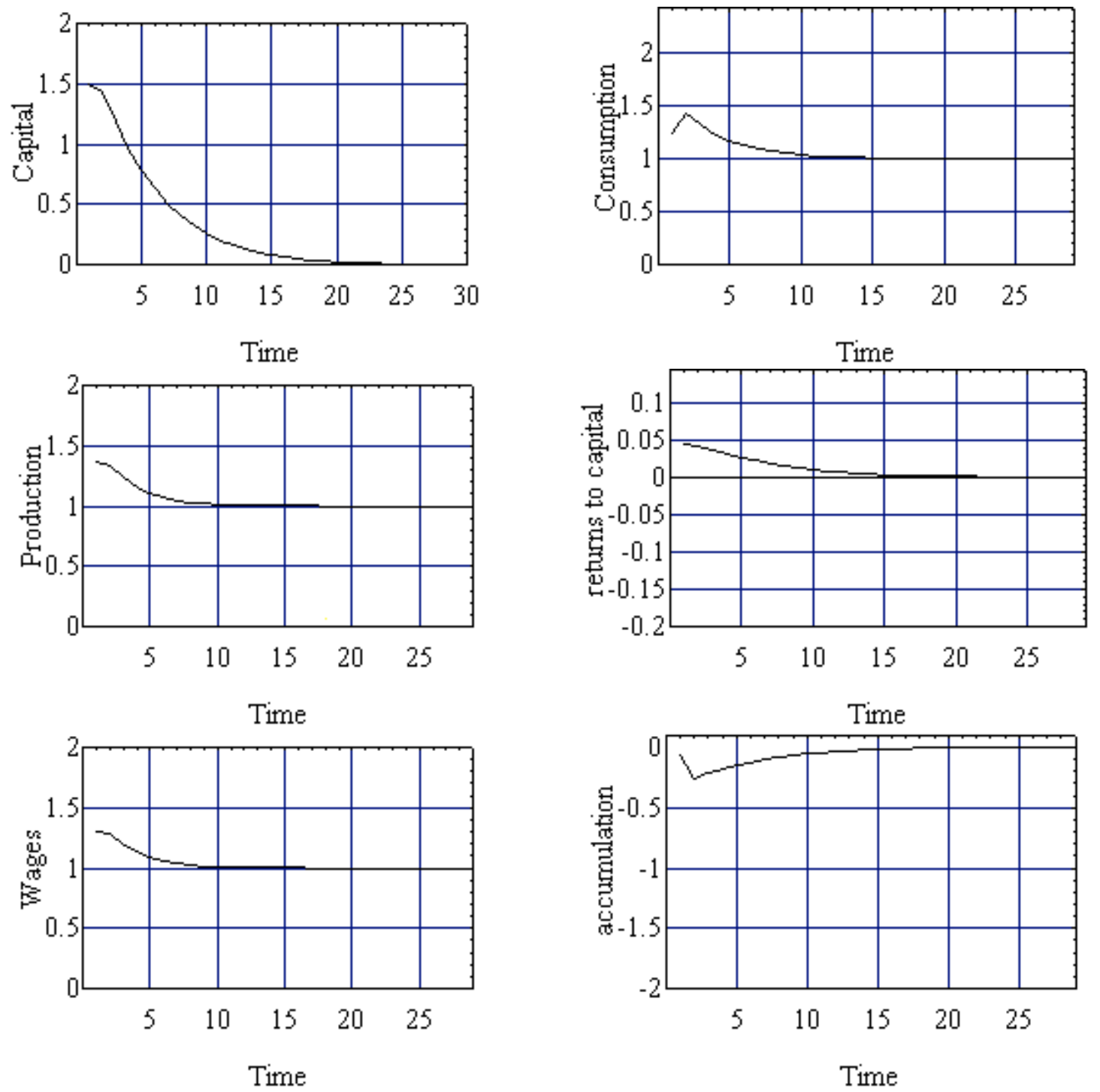

Phase Diagram

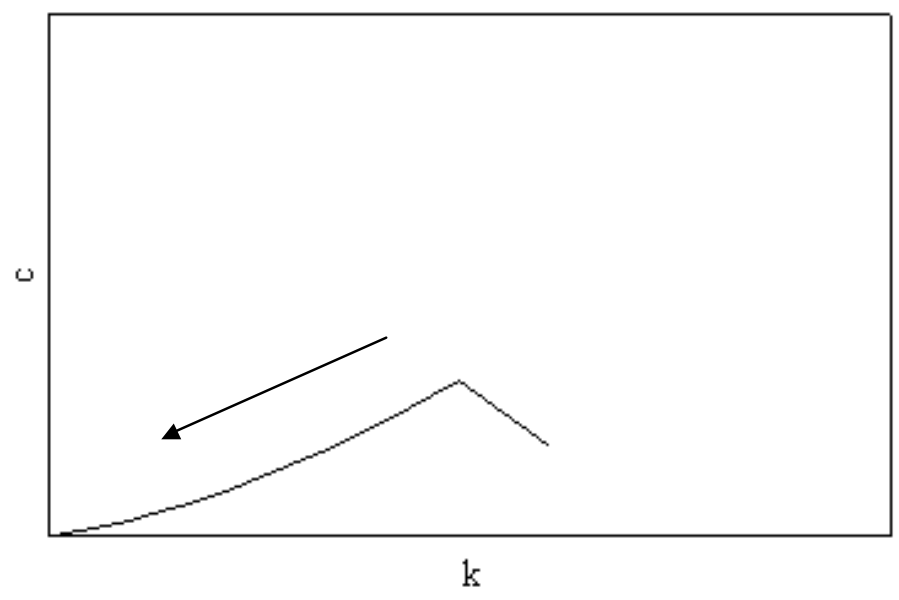


Figure VII:
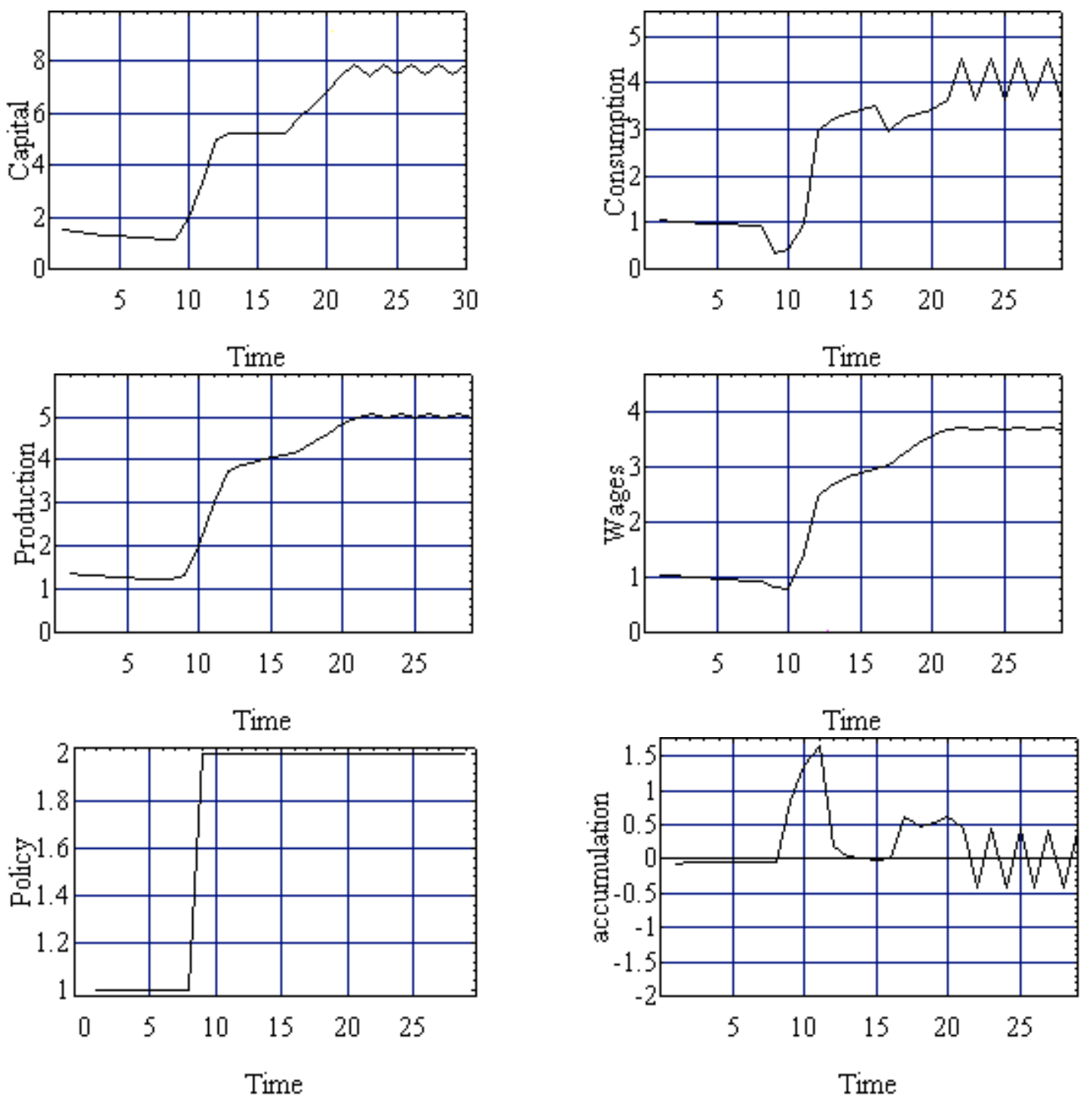

Time

Phase Diagram

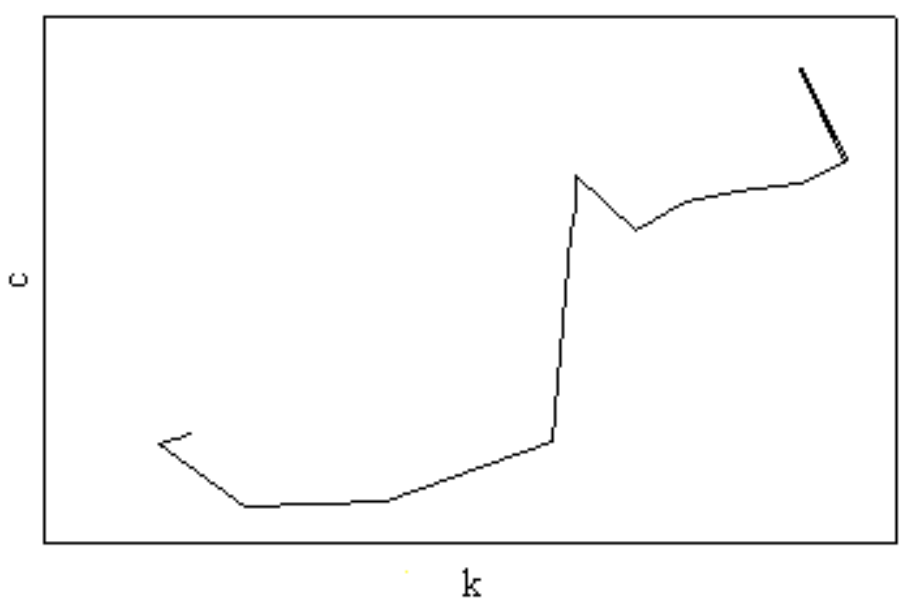


